$\xi=-1$

\title{
Brand in the Philosophical Sense: from Object to Person
}

\author{
Artur Dydrov $^{1}$, Anatoly Nevelev ${ }^{2}$, Vera Neveleva ${ }^{2}$, Ekaterina Milyaeva $^{1}$, Regina Penner $^{1 *}$, Dmitry Solomko $^{1}$ \\ ${ }^{1}$ South Ural State University, 76 Lenina pr., Chelyabinsk, 454080, Russian Federation \\ ${ }^{2}$ Chelyabinsk State University, 129 Bratiev Kashirinykh st., Chelyabinsk, 454001, Russian Federation
}

*Corresponding author E-mail: dydrov.a@mail.ru

\begin{abstract}
Under the influence of the values of Western European civilization, the life of contemporary human has been gradually shifted from the supremacy of the practices of material consumption to the practices of self-realization. It is interesting to understand the phenomenon of brand, which goes beyond researches in economics and marketing (D. Aaker, J. Trout and D. Ogilvy). Brand is able not only to take away the individual's world but also helps the individual to stand out, to overcome the ordinary life through brand's universality which contributes to the establishment of mutual understanding between people. Philosophical anthropology and its theories by $\mathrm{H}$. Marcuse, J. Ortega y Gasset or E. Fromm can become the basis for a new interpretation of brand as a socio-cultural phenomenon that plays a significant role in the human everyday life. The authors substantiate the thesis that brand and human-brand, in particular, can be tools of assembly and can be used as a reference for other people, can overcome the crisis of the identity of modern human.
\end{abstract}

Keywords: brand, functions of brand, human brand, identity, philosophical anthropology.

\section{Introduction}

The modern consumer society and the mass culture are objectively conditioned and historically determined by the development of the Western European civilization and capitalistic relations. The current trends in the development of society, i.e. the expansive growth of global communications, focus of the Western culture on innovation and on the maximum of human's self-realization in all spheres of his/her activity, the priority of individual freedom significantly affect the relations between producers and consumers of goods and services. The manufacturers' attempts to unify the needs of people have come up with the arising of various individual consumer demands with which every producer who is striving for success in the market, material and spiritual, must now regard. This reveals a gradual and regular turn from mass and impersonal goods to goods, personifying the individuality of both producer and consumer.

According to G. Hill, brand today is a significant component in various spheres of public life and everyday life of a person [1] Initially, its history was associated with commodity-money relations, the relations between producer and consumer. This relation gradually stipulated the dominant position of the consumption with changing their content. The modern society is oriented to the mass consumption, but at the same time - to the individual consumer priorities. Brand actively participates in the process of "marking" the consciousness of a person as a consumer, in formatting his/her value world and preferences, creating his/her "own" consumer and being responsible for him/her [2].

Nevertheless, any kind of consumption is the production. A certain mythology, connotative meaning, a kind of "implicit knowledge" that is important to a person is always associated with a brand. That is why it is possible to talk about the humanistic functions of brand, to interpret this phenomenon from the point of view of its cultural potential and opportunities in human's "cultivating". In this case, brand appears not only as a means of con- sciousness manipulating, providing profitable consumption but also as a cultural form, a means of "production" of a person, his/her personality. This corresponds to the general logic of history, in which the dominance of the production of materialized forms should in one way or another be replaced by a period of domination of the production of people (including the production by means of things). The priority of the living over the materialized must be designated. In brand, there is always a "voice" of the consumer, i.e., of human living needs. In addition, brand always refers to the person, through whom it appeared, to his/her personal history, the history of his/her success, for instance. This is the basis of concreteness of brand, not its abstractness.

The most important function of a brand with its history and mythology behind it is to induce a person to self-produce of his/her own personality and his/her own life history. Modern people actualize the nomadic mode of existence; nomadically they often "roam" on brands. This can be interpreted not as a mere fashion following, but as an intuitive or conscious search for "your own" which would correspond to the individuality in all its manifestations. This brings the meaning of brand beyond the limits of marketing practices, actualizes the phenomenon of brand from the point of its humanistic interpretations.

The relevance of this paper is expressed in several positions: firstly, brand can and should be the subject of philosophical and, in particular, philosophical-anthropological interpretation. Brand is inextricably linked with the subjectivity of human and affects his/her inner world. The nature of brand as an instrument for the formation of the human value world cannot be described with the help of the thesaurus of economic sciences. Secondly, in the foreshortening of philosophical anthropology, brand is a means of producing personality and assembling a person. Brand can be a guide in the realization of a person's own life project. Finally, with the help of philosophical and anthropological tools, the phenomenon of the human brand has been studied. The human brand is the result of hard work and auto projection. This phenomenon is considered as a tool for the evolution of the spiritual world of the 
individual and overcoming the stereotypes of the consumer society. Philosophical understanding of the phenomena of brand and the human brand is necessary in order to deduce the auto projection from the contexts of entrepreneurship and business.

The research problem lies in the fact that there is a contradiction between brand's relevance in the individual's life and modern society and the lack of a holistic picture of brand understanding.

\section{Materials and Methods}

The problem of brand as an important component of modern market relations has been actively studied by theoretical and applied marketing research since the middle of the XXth century, which is caused by the revolutionary development of information technologies in the production and economic sphere of society as a whole. As a result, gradually formed a whole trend called brand management, the formation of which is laid not only in economic, but also in sociological and psychological researches. Among the researchers on brand as an economic phenomenon there are such wellknown figures as D. Aaker, J. Trout, D. D'Alessandro, J. Riderstelle, N. Klein and D. Ogilvy. Moreover, the study of brand as a phenomenon of the consumer society itself and an important component of modern consumer practices can be based on the understanding of fundamental and applied research on the management of market relations such as the works of D. Aaker, L. Keller, S. Hurrell, D. Scholarios, R. Lunardo [3], J. Moulard [4].

Economic and technical achievements radically changed the objective and cultural world of human. That is why it is necessary to turn primarily to fundamental research of the features of capitalism and of the understanding of human in the capitalistic system by K. Marx and F. Engels. Furthermore, in the study of the phenomenon of brand from the standpoint of philosophy it is also necessary to appeal to widely known works of representatives of Western European thought, whose works were devoted to the problems of the mass culture, the society of consumption and the problems of everyday life (J.-P. Sartre, R. Barthes, J. Baudrillard, J. Lacan, H. Marcuse, J. Ortega y Gasset, F. Jamieson, R. Lifton, E. Fromm).

R. Barthes's semiotic concept of mythology, translated via secondary (connotative) meaning, and V. Stepin's idea of human as a semiotic system were used as a theoretical basis for the study. The philosophical-anthropological approach was implemented with the support of R. Lifton's ideas about the set of social roles of the person and the problem of self-identification, L. Motorina's idea about the fundamental anthropological constants (self-transcendence, creativity, openness to the world), J. Baudrillard's ideas about the space of symbolic exchange and simulacra.

The methodological basis of the study is connected with the use of the dialectical approach: the dialectic of the essence and existence of human, proper and general in human existence. Moreover, the hermeneutic approach and, in particular, the method of interpretation, were used in the analysis of the phenomenon of brand. The study of the phenomenon of brand was carried out using a semiotic approach. Brand is treated as a semiotic system, the unity of the primary (denotative) and secondary (connotative) meanings. Finally, general scientific methods such as comparison, analysis, extrapolation, synthesis, induction and deduction were used.

\section{The mythology of brand}

\subsection{Signified and signifier of brand}

The majority of researchers admit that brand cannot be identified with a trademark [5], [6], [7]. Moreover, the specificity of brand cannot be reduced to the popularity of a particular trademark. This would lead to unjustified emphasis on the representing of the object, not on the referent. The mark replaces object not in all respects, but correlates with a certain quality, property or idea of the referent. The phenomenon of brand must be regarded as the unity of the mark, the commodity and the person [8].

Denotation of brand conveys verbal and iconic messages. In the words of R. Barthes, the first has a "linguistic substance" [9]. Rolex slogan is laconic and consists of only two words - "perfection" and "prestige". Pepsi slogan - "take everything from life" and Coca-Cola's advertising with the words "always Coca-Cola". As a rule, the verbal message of brand is laconic and easy to remember. A visual imagery corresponding to the verbal message expresses the iconic message. For example, Coca-Cola's advertising employs images of Christmas and Santa Claus. Both verbal and iconic messages have primary (literal) and secondary (connotative) meanings [10]. One of the main brand makers' tasks is to induce a product or service consumer to read a second meaning in the first place. R. Barthes in "Rhetoric of the Image" used the neologism "Italianicity" to denote the connotation in Panzani's advertising. Coca-Cola's advertising is unlikely to employ neologisms to denote connotation. The secondary meaning can be expressed, for example, by the words "festivity" and "familiality".

Unlike brand sign, the signs of unbranded goods often represent goods in a "false" light. On the package of a product containing hazardous ingredients could be seen inscriptions like "highest quality", "product number 1". Images on packages do not always correspond to the appearance of the goods. Signs of unbranded goods often distort the real state of things. In the words of J. Baudrillard [11], if a sign disguises or distorts reality then it is a second stage of simulacra.

The unique brand denotation is firmly connected with the signified, that is, with a sign in the person's mind, with the image of the product, service, company policy, etc. Brand denotation is often transferred from its native context to a foreign one. For example, the Mercedes sign used for key fobs and the Playboy logo is placed on T-shirts. Despite this, the connection between the signifier and the signified is not torn. Moreover, brand's mark transferred to a foreign context can influence this context. A person in a T-shirt with a rabbit muzzle silhouette seems to pose himself/herself as a ladies' favorite, and the owner of key fob as a car enthusiast and the connoisseur of the car's quality. Although, all these attributes could be a completely random or simply following the person's own taste or fashion.

The connotative message of brand is broadcasted for a specific target audience. In the paper "Brand and branding in the life of modern society" Y. Zapesotsky [12] illustrated this statement with the magazine "Playboy" as an example. The magazine was founded in 1953. The class of wealthy Americans who multiplied their capital because of the economic recovery in the 1950s was its target audience. The majority of wealthy Americans were not able to perceive the cultural values of the establishment. Despite this, they wanted to be like the elite. The authors of journal papers wrote about expensive shoes, luxury suits, cars, watches, etc. The publication quite satisfied the demands of "new Americans". A person who was literally called self-made-man achieved through his own work, talents and unique personality traits. However, this self-made-man understood nothing in art, philosophy or science but he/she sought at least external resemblance to the elite. Enjoying life in all its manifestations and respect from others were the worldview cornerstones of "new Americans".

\subsection{History of the company in the brand mythology}

As was mentioned earlier, brand expresses a certain mythology. Unlike ordinary trademarks brand always has a history. The richer the history of brand is, the stronger its market position. The rich past of the goods is the guarantor of its high quality and unique properties. According to R. Barthes, in the myth the story "disappears". The French thinker compared the story to the "ideal servant", implicitly fulfilling the duty and disappearing at the appearance of the master [9]. However, the mythology of brand, on the contrary, needs a history. Directors and managers of companies, as a rule, take pride in the past and periodically recall it during press 
conferences, promotions and other events. The history of brand connects several generations. Having a rich past, brand evolves and attracts the attention of people of different ages. Coca-Cola drinks appeared in the XIX century. During the XX century, because of the advertising strategy, the composition of the drink and the shape of the bottle have been changing dramatically. Despite this, the products of Coke are still easily recognized. Today, at the beginning of the XXI century, Coca-Cola confidently positions its product as a drink that gives a sense of the family unity and fun time with friends. More than a century-long history of the company's existence allows uniting representatives of three or four generations.

The significance of brand is expressed in the fact that it acts as a value reference. Brand helps to fill the human life with the meaning that was not originally set. Mythology of brand translates various personally significant values, from material prosperity to the development of intelligence [13].

Swiss company Chopard exists since 1860 and is known for its jewelry and expensive watches. The company prides itself on producing men's and women's watch collections. All watches produced by the company are advantageously distinguished by high accuracy. The clock mechanism of any series is designed by the company's mechanics in conditions of strict secrecy. The mythology of brand Chopard is based on the high quality of its watches and, accordingly, on its price, business style, luxury, refinement of taste and high income of the client. The target audience of such watches is businessmen, top-managers and officials of high ranks. The product emphasizes that the owner appreciates time and plans his day. This model is used by many manufacturers of luxury goods. The brand value in the luxury segment is determined by the high quality of the presented product, by the combination of unique knowledge and exclusivity in it, an individual approach to the consumer [14].

The American corporation Apple has bet on the availability of gadgets, as well as on their constant updating. One of the company's main ideas boils down to the fact that smartphones contribute to the development of intelligence. They can be purchased by anyone who is interested in the surrounding world and continuously expanding their horizons. People naturally aspire to knowledge, but many people stop along the way. The smartphone should emphasize that its owner has not lost interest in the world. This mythology of the smartphone differs significantly from the mythology of cell phones, providing only fast and high-quality connection of users.

The phenomenon of brand has a history much older than modern marketing, PR and direct branding, which became significant in the life of the West European society in the mid of XXth century in the heyday of the so-called prosperity states and the capitalist economy. This period is marked by the intensive development of the means of communication, the triumph of mass culture, the dominance of consumption, which influence the human values from which the basic ones are self-realization and constan maintenance of a high level of competitiveness. These values demanded both in the labor market and in other forms of social relations, for instance, in friendship, creative team of interests or family.

\subsection{Historical stages of brand}

Speaking about the history of brand, it is necessary to identify three important stages related to the emergence of Western European culture. The first stage is connected with pre-industrial development, with manual labor, when things were unique and many of them, weapons for example, had given their own names. At this time, the stigma of the master symbolized the specific qualities of not only the sword itself, but also the quality of the person who created the thing: his/her skill, diligence, talent. In fact, there was a strong connection between the thing and its creator. This caused a peculiar emotional connection between the buyer and the manufacturer. In the product of labor, unique human abilities were iden- tified.

With the advent of the second stage, from the appearance of the first manufactories to the conveyors, in the era of industrialization, mass production of consumer goods, each manufacturer had an interest in ensuring that the consumer needs precisely his/her goods. That is why at the end of the XIXth century the phenomenon of brand appeared on the market.

Brand is not only a means of identifying goods. One can brand anything, from milk bags to politicians. At any request of society, even from the opposition and counterculture, the producers of material and spiritual goods responded by creating a new product, which was labeled by brand. As a result, brands have become a very effective means of managing a person. Many of them brought incredible incomes to their creators and owners. It is the situation when the producer during the half of the XX century controlled the behavior of the buyer through the total branding of goods and services. This process was rigidly ridiculed by N. Klein in her book "No logo: Taking Aim at the Brand Bullies" [15] in which she had investigated consumer behavior in the USA.

But in the transition period from the end of the XXth century to the new millennium, with the development of communication technologies, at the stage of emergence of the postindustrial society, it became clear that it was impossible to manage the behavior of consumers with the help of classic advertising technologies. People do not want to consume a mass product, they refuse to be ordinary buyers, the so-called "target audience", the conquest of which seems necessary for any manufacturer. The modern consumer wants an individual approach, appealing to his/her needs and unique features. Access to the Internet makes it easy to find out exactly what the manufacturer is deceiving in advertising, and this leads to rational consumer practices. In connection with the orientation of modern Western European culture to the priorities of self-development, individualism, self-expression, person's daily life often becomes the art of owning things. The symbolic language of things helps consumer to express his/her social status, to convey the mood, emotions, tastes and attachments. In the preindustrial era, brand told about the originality of the creator of the thing, and today it narrates about the owner of the thing, pointing out the individual features of his/her thoughts, lifestyle, preferences and desires.

\subsection{Functions of Brand}

It is obvious that not only things but also people can act as semiotic systems. Performing the function of a sign system, a person broadcasts a certain program of activity. According to V. Stepin [16], human is a semiotic system if his/her actions become an example for imitation. The actions of the master, showing his/her student some of the techniques of work, the actions of an adult copied by a child, the imitation of a pop star are just a few examples of the functioning of human as a semiotic system.

The society encodes certain patterns of activity, behavior and communication. Demonstration of these samples is one of the most ancient and effective ways of translating the experience. Modern media technologies make broadcasting fast and access to patterns of behavior is easy. In other words, people easily learn anything about the actions of movie stars, big businessmen, political leaders, famous sportsmen, musicians, etc. Various "samples" of "know how to act" are broadcasted daily from television screens and personal computer monitors [17].

Any brand performs several functions in the individual's daily existence:

1. Individualizing helps a person in the existing variety of things and information to determine the choice, making the result of this choice in the property of I. In this case, the person distinguishes himself, becomes different from others.

2. Value-oriented function indicates that brand can act as a marker of the person's value priorities, both in material and in spiritual consumption. Brand translates certain collective values and "encourages" a person to follow any patterns of behavior, 
norms and rules of life, i.e. affects the formation of the consumer's worldview.

3. Socializing - the use of brands allows a person to form and express his or her own individuality. Simultaneously, this means cultural identification and implies the correlation of person with a cultural community, group.

The most important function of brand, with its history and mythology behind it, is to induce a person to self-produce his/her own personality and his/her own life history. After all, a person lives in a very difficult situation - his/her symbolic status is expressed through things and behaviors that actually dictate how he/she should be: a brutal man in a powerful car or a wildlife protector in a natural cotton T-shirt. Going over social roles, instantly turning from one to another, a person is likened to the mythological Proteus, who changed his body and could not confidently answer the question of who he really is. R. Lifton [18] designated this phenomenon as "Protean Self".

Brand acts on the person through the mythology that it transmits. In particular, as a bearer of mythology, brand can be an object of interpretation. Brand can be considered as a mental construct, which contains a set of meanings, as well as a kind of value reference, a regulator in the process of human's realization of consuming practices, both material and spiritual.

There are different levels of perception and the possibility of reading brand. The meaning of brand interpretation can be different However, today it becomes obvious that brand can be viewed not only through the prism of the economy (as a means of identifying and promoting a particular product), but also through the prism of anthropology.

Brand is a symbolic construction, behind which stands the person, its creator. Brand is a creative product expressing the creator's ideas aimed at satisfying living human needs. Brand acts as a mediator not so much between a person and a thing to which brand refers, as between a person such as creator and consumer. Consuming a thing, a person consumes what is behind it, the living human energy (views, life priorities, goals, values), the energy of the creator of brand [19].

Brand is a tool for self-actualization of personal principles, the manifestation of individual qualities. Behind brand is a real person with all his or her unique characteristics. At the same time a lot of significant social and cultural meanings turn brand not only into an object of sale and purchase but also into a special cultural form that are gathered around brand.

The cultural form, in general, and brand as a cultural form, in particular, is a structural formation, the stable features of which are always reproduced in culture but can have different content, depending both on the personality of the brand creator and on the requests of its consumer. Therefore, it is necessary to take into account that a more appropriate sense reading of brand as a cultural form can be realized only in its natural cultural context. Brand for its author becomes a means of identification. However, creating a brand the creator obviously does not use it as such a tool. In brand, the relationship between the individual and the universally significant is revealed: personal properties acquire supraindividual significance. It is obvious that today the world in the sense is ambiguous, therefore brand's value content directly depends on its natural social and cultural contexts.

The person, who creates brand, guesses in his/her personal experience something socially significant. In brand there are individual (branded unique characteristics of its creator) and individual (that the creator of brand guessed as socially significant), who allows brand to be relevant. After all, any brand as a cultural form is under the continuous influence of historical selection, which presupposes, first of all, the selection of the most acceptable ways of satisfying one or other requests of society. In the anthropological sense, brand can serve as a kind of standard in defining life attitudes, building value priorities for human existence, which will allow a person oriented to it to feel himself as an organic part of society and culture, while preserving his/her freedom, integrity and diversity of is/her behavior.
The most important function of brand in the anthropological sense is expressed in inducing human to take an independent action, to manifestations of subjectivity towards him/her. A person must become a "self made man". It must be remembered that the creator of brand is not so much the result of imitating the samples, but rather the result of the cultivation of the individual, that is, deliberate and consistent cultivation of oneself, through the systematic implementation of a series of conscious actions aimed at selfdevelopment and self-realization. But along with this the author of brand does not pursue the goal that his/her personal characteristics become brand [20].

\section{Conclusion}

Brand, filled with existential meaning, stands such a test with social experience, as it has a constructive, meaningful and humanforming side. In promoting himself/herself through brand, a person can become "the human brand" himself/herself. That is why, brand becomes a benchmark, a kind of standard for the person (consumer), modern to him/her and consonant with his/her intuitive or conscious search for himself/herself, his/her existence, his/her "true self".

With the act of putting his/her own meanings into brand or waking them up through brands, the existential path begins - the way of returning person to himself/herself from a multitude of relationships to his/her true self. The way of uniting an individual and supra-individual, restoring the integrity of the inner world are essential for a modern human who is living in an infinitely diverse world of culture.

In the modern social and cultural situation, there is definitely the possibility of the existence of the human brand, combining some of the significant features of brand as a phenomenon of the economic sphere (respectability, the representation of a certain life reputation and life path, the mythologization of a person's biography, the official registration of brand elements as an object of ownership) with concrete-single expression of such fundamental anthropological constants as self-identity, authenticity, openness to the world and creativity. In fact, the human brand expresses itself a form, model of activity, a value model that is in demand at a certain point in time, in specific social and cultural conditions.

Brand as a cultural form is mediated by the "spirit" and content of culture and is itself embedded in it, being its phenomenon. The functioning of this cultural form as the human brand can be one of the means of assembly for other people, because of which they are able to find their unique way of self-realization in society, culture. The human brand is a unity of a mentally constructed and objectively real because it contains a name, a history and mythology associated with a person, but also his/her actual concrete personality and creative product. The presence of these genuine, real elements in the human brand transforms human into a transgressive phenomenon, taking him/her beyond purely mental constructions. It is necessary to understand that the popularity, social status and income of the human brand are the tip of the iceberg. Behind these obvious things, there are hidden unique qualities of the individual, hard work and determination, independence, responsibility for the decisions made. It is this "added value" in the human brand that can be the guide, that will help others to find options for overcoming the very narrow limits of human existence set by society, by deliberately working on themselves and searching for new ways of self-actualization.

\section{Acknowledgement}

The first draft of this article was originally presented at Supervision with Philosopher, Institute of Humanistic and Existential Psychology, June 10-12 2017, Vilnius. We thank all the participants for their stimulating questions. Moreover, the article was 
supported by Act 211 Government of the Russian Federation, contract No 02.A03.21.0011.

\section{References}

[1] Hill G, Ibsen H (1996), Brand. London: Penguin.

[2] Kreuzbauer R (2002), Theoretical Part, in Design and Brand. Deutscher Universitätsverlag.

[3] Lunardo R, Gergaud O, Livat F (2015), Celebrities as human brands: an investigation of the effects of personality and time on celebrities' appeal. Journal of Marketing Management, 31(5-6), 685-712.

[4] Moulard JG, Garrity CP, Rice DH (2015), What makes a human brand authentic? Identifying the antecedents of celebrity authenticity. Psychology and Marketing, 32(2), 173-186.

[5] Aaker DA (1997), Should you take your brand to where the action is? Harvard Business Review, 75(5), 135-142.

[6] Aaker DA, Joachimsthaler E (1999), The lure of global branding. Harvard Business Review, 77(6), 137-144, 217.

[7] Hurrell SA, Scholarios D (2014), "The People Make the Brand". Reducing Social Skills Gaps Through Person-Brand Fit and $\mathrm{Hu}-$ man: Resource Management Practices. Journal of Service Research, $17(1), 54-67$

[8] Lieven T (2018), A Brand as a Person, in Brand Gender. Palgrave Macmillan.

[9] Barthes R, Heath S (1977), Image, Music, Text: Rhetoric of the Image. New York: Hill and Wang.

[10] Barthes R (1972), Mythologies. New York: Farrar, Straus and Giroux.

[11] Baudrillard J (1994), Simulacra and Simulation. Michigan: University of Michigan Press.

[12] Zapesotsky Y (2009), Brand and branding in the life of modern society. National Interests, 5, available online: http://ni-journal.ru/ archive/14928136/n_5_2009/e30de777/0717e9ec/, last visit: July $31,2018$.

[13] Stinnett RC, Hardy EE, Waters RD (2013), Who are we? The impacts of anthropomorphism and the humanization of nonprofits on brand personality. International Review on Public and Nonprofit Marketing, 10, 31, https://doi.org/10.1007/s12208-012-0087-z.

[14] Kernstock J, Brexendorf TO, Powell SM (2017), Introduction: Luxury Brand Management Insights and Opportunities, in Advances in Luxury Brand Management. Palgrave Macmillan.

[15] Klein N (2000), No Logo: Taking Aim at the Brand Bullies. Canada: Vintage.

[16] Stepin V (2011), Civilization and Culture. Saint-Petersburg: SPbGUP.

[17] Schedrovitsky G (1967), On the method of semiotic study of sign systems. Moscow: Semiotics and Eastern Languages.

[18] Lifton RJ (1993), The Protean Self: Human Resilience in an Age of Fragmentation. New York: Basic Books.

[19] Wee TJ (2004), Extending human personality to brands: The stability factor. Journal of Brand Management, 11, 317, https://doi.org/ 10.1057/palgrave.bm.2540176.

[20] Guido G, Peluso AJ (2015), Brand anthropomorphism: Conceptualization, measurement, and impact on brand personality and loyalty. Journal of Brand Management, 22, 1, https://doi.org/10.1057/ bm.2014.40. 